\title{
The contribution of a gender perspective to the understanding of migrants' health
}

\author{
Alicia Llácer, María Victoria Zunzunegui, Julia del Amo, Lucía Mazarrasa, Francisco Bolůmar
}

J Epidemiol Community Health 2007;61(Suppl II):ii4-ii10. doi: 10.1136/jech.2007.061770

In 2005 women represented approximately half of all 190 million international migrants worldwide. This paper addresses the need to integrate a gender perspective into epidemiological studies on migration and health, outlines conceptual gaps and discusses some methodological problems. We mainly consider the international voluntary migrant. Women may emigrate as wives or as workers in a labour market in which they face double segregation, both as migrants and as women. We highlight migrant women's heightened vulnerability to situations of violence, as well as important gaps in our knowledge of the possible differential health effects of factors such as poverty, unemployment, social networks and support, discrimination, health behaviours and use of services. We provide an overview of the problems of characterising migrant populations in the health information systems, and of possible biases in the health effects caused by failure to take the triple dimension of gender, social class and ethnicity into account.

See end of article for authors' affiliations

Correspondence to: Alicia Llácer, Centro Nacional de

Epidemiología, c/Sinesio

Delgado no 6 'pabellón

12), Instituto de Salud

Carlos III, 28029 Madrid,

Spain; allacer@isciii.es

Accepted 16 July 2007
W omen and girls have played an important part in migratory processes throughout history, yet despite their numerical importance, global estimates of the extent of female migration were not available until recently. ${ }^{1}$ United Nations Population Division estimates for the period 1965-2005 show that for more than 40 years, female migrants have been almost as numerous as male migrants, rising slightly from $47 \%$ in 1960 to $50 \%$ in 2005 . Globally, 191 million men and women-accounting for close to $3 \%$ of the world's population-were international migrants in 2005, and of these 95 million were women. Nearly two-thirds of the migrant population have settled in developed countries, where the feminisation of migration is higher $(52 \%)$ than it is in developing regions $(46 \%) .^{2}$ This is so because in developed countries female migrants can be admitted both as "dependent" wives and as "independent" women integrated into the workforce, whereas in developing countries women migrants are usually admitted only as required by the labour market. Twenty countries on five continents received two-thirds of all international immigrants. Human development, gender development and equality indicators for these countries are shown in table 1. Most, though not all, such countries rank high in terms of development indicators, as was to be expected given their appeal to migrants seeking a better life. Ranking in terms of gender equality is more varied, however: in gender empowerment, over half rank low or have no available indicators.

Women's impact on the international flow of migrants is important from both a quantitative and a qualitative perspective: a large proportion of migrant women move to other countries in search of employment for themselves, and not necessarily to join their husbands or other family members. This gender focus on the migratory phenomenon has spread to other areas, such as migratory theories ${ }^{3-5}$ and women's contribution to economic development, ${ }^{67}$ culminating in the recent report of the United Nations Population Fund (UNFPA) on women and international migration. ${ }^{8}$

Gender is understood as the different roles men and women assume in a historically and socially determined unequal power structure. Analysis from a gender perspective involves recognition that men and women operate in a historically configured relationship of subordination which influences all aspects of their lives, rendering them differentially vulnerable. Asymmetry between the sexes arises from, among other things, unequal social and economic valuation of productive work (gainful employment) and reproductive work (unpaid work, such as household tasks and caregiving). ${ }^{9}$ This sexual division of labour causes men and women to assume different roles and responsibilities that involve differential health risks. ${ }^{10}$ Gender differences occur in all cultures, though they vary in intensity depending on the time and place. ${ }^{11}$ They are of fundamental importance in the migratory process and are the basis for other relationships of subordination. The migratory process itself affects gender relations dialectically, modifying them in the places of origin and destination, at times in a way that is contradictory. Thus, it is critically important to understand how migration may change patriarchal relations and whether it serves to reinforce or rupture them. ${ }^{3}$

United Nations recommendations ${ }^{12}$ define an international migrant as any person who changes his or her country of usual residence. We focus on international migratory flows that are voluntary, motivated by a desire for socioeconomic improvement, and primarily directed towards developed countries. Within country migrations and refugee situations are a different issue that is not addressed here. A related concept that needs to be outlined is that of ethnic minority, as there are overlaps between populations belonging to ethnic

Abbreviations: GDI, gender development index; GEM, gender empowerment measure; $G G l$, gender gap index; HDI, human development index; UNFPA, United Nations Population Fund 


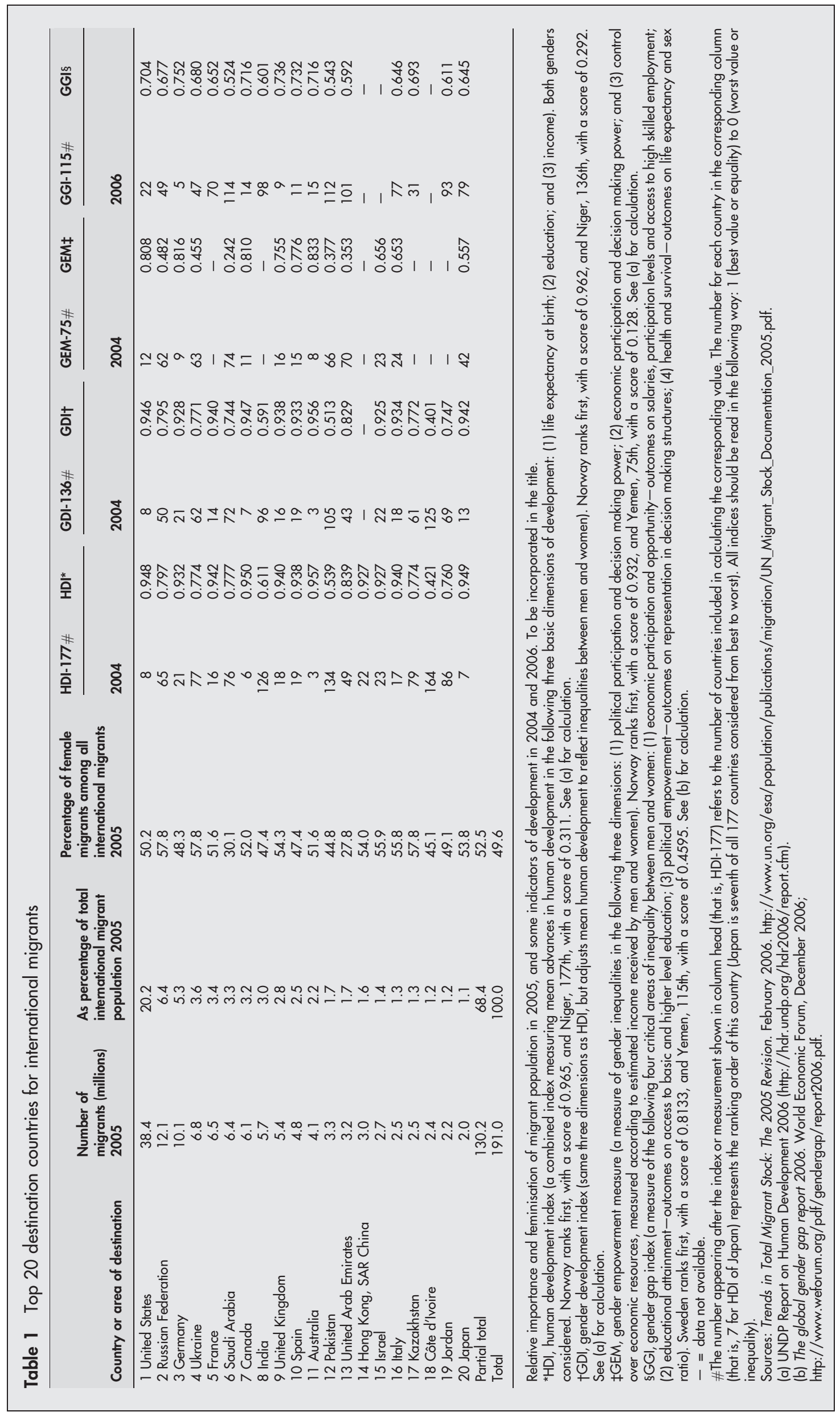


minorities and migrants. Ethnic minorities include established minorities as well as those resulting from recent migratory waves. Migrants and their descendents, sometimes termed second or third generation migrants, often become part of the ethnic minority community.

Arguably, one of the most inadequately studied areas from a gender perspective is the health and wellbeing of migrant populations, ${ }^{13}{ }^{14}$ possibly because economic migration is characterised by the selection of populations that are young, healthy, of reproductive age, and capable of joining the workforce. It is thus important to understand the way in which gender interacts with other determinants, to explain how, why and when such populations' health deteriorates and how to develop preventive mechanisms. This paper addresses the importance of and the need to integrate a gender perspective into epidemiological studies on migration and health, outlines conceptual gaps and discusses some methodological problems.

\section{HEALTH OF MIGRANT POPULATIONS}

Recent migrants have been reported to enjoy better health than do the host country populations. This phenomenon, known as the "healthy migrant effect," is attributed to the various selection processes that labour migrants undergo before arriving at their destination. ${ }^{15}$ Since most people go to another country expecting to work, those who most frequently migrate are the fittest and best able to survive the journey. In regularised migrations, good health is required to pass comprehensive medical screening before entry. It has been observed, however, that some time after migration, immigrants' and nationals' health patterns converge ${ }^{16}$ and that, for some health conditions, such as self rated health, immigrants fare worse. ${ }^{17}$ Nevertheless, this convergence pattern seems to vary across countries and immigrant populations, ${ }^{18}$ and in some instances has not even occurred. This is the case of the so called Latin paradox among residents in the United States, where, despite worse socioeconomic conditions, these people display lower mortality rates or better pregnancy outcome indicators. ${ }^{19-21}$ The same effect has been described in Europe for Turks in Germany and Moroccans in France. ${ }^{22}{ }^{23}$ In an attempt to explain this paradox, several methodological problems have been cited, such as selection caused by the "unhealthy remigration effect" (salmon bias). ${ }^{21}{ }^{24}$ Longitudinal studies on Irish migrants in the United Kingdom report a different mortality pattern, albeit with higher mortality persisting in subsequent generations after adjustment for socioeconomic conditions. ${ }^{25}{ }^{26}$ To our knowledge, the healthy migrant effect has not been analysed through a gender lens.

Three models have been proposed to explain the decline in immigrant health over time. ${ }^{27}$ Firstly, the convergence model posits that exposure to physical, social and cultural influences leads to a shift in migrant morbidity and mortality towards that of the host country's native born population. Secondly, the resettlement stress model postulates that stressors, such as poverty, unemployment, lack of social networks and lack of access to services, have an adverse effect on health, which is particularly strong for immigrant populations. Lastly, the interaction model postulates that pre-migration and postmigration stressors and the strategies adopted by individuals, their families and society at large to cope with the immigration experience interact to maintain the immigrant's health. These models are not mutually exclusive, and their proposed mechanisms may be acting simultaneously. The challenge lies in how they could be expanded to encompass analysis of gender differences.

\section{HEALTH DETERMINANTS IN MIGRANT POPULATIONS}

Three dimensions-gender, ethnicity and social class-form the basis of social inequalities in health. ${ }^{28}{ }^{29}$ These dimensions are closely interrelated and are each associated with specific risks to health and differential vulnerability during the population's lifetime, before and after migration. The ways in which these three stratification forces interact depend on the empowerment of individuals, organisations and communities. In this context social class is considered as socioeconomic position assessed by occupation, education and/or income since most epidemiological studies have used this approach. Indeed, a World Health Organization review ${ }^{30}$ of the effectiveness of empowerment to improve health defined the term as "a process by which people, organisations and communities gain mastery over their affairs" and considered that women's empowering interventions "... have shown the greatest impact on women's quality of life... and on improved child and family health."

In the case of female migrants, empowerment involves being able to change their relation of male dominance to one of equality in their personal relationships as well as in the social and political sphere. ${ }^{31}$

Although economic reasons are a major determinant of migration, push and pull factors have gender specificity. Gender determines the probability of emigrating, combining individual factors (age, birth order, race/ethnicity, urban/rural origin, marital status, reproductive situation, family role and position, education, professional training, work experience and class position), family factors (structure, size, composition and family relationships) and social factors (community norms and cultural values that influence whether, how and with whom to emigrate). Consider, for example, the different situations of women who migrate for economic reasons and are the primary family caregiver ( single parent homes) yet have to leave their children behind because they cannot look after them adequately, compared to those who emigrate alone to Western countries to gain personal autonomy and avoid the traditional gender roles in their countries of origin, or those who follow their husbands so that the family can be reunited.

In studying the determinants of health in migrant populations, it is important to consider the entire migratory trajectory-that is, determinants in origin, transit and destination and the widespread notion that health determinants have a hierarchical structure, ranging from the more distal and contextual, such as the socioeconomic conditions prevailing in the countries of origin and host countries, to the more proximal and individual, such as newly adopted health behaviours.

\section{Health determinants in countries of origin and transit} Migrants moving to industrialised countries have been exposed to different morbidity and mortality patterns, characterised by higher mortality rates and a higher burden of communicable diseases and reproductive complications in women. ${ }^{32}$ The role of gender related contextual determinants is particularly relevant in developing countries, where women's social position places them at a far greater social disadvantage compared with men than their counterparts in industrialised countries. Women have less access to basic rights, lower rates of education and employment, lower salaries and less access to healthcare services. $^{83}$ Childcare and domestic duties fall almost exclusively on women. These limitations, together with cultural norms involving taboos and strong social pressures, exert a great impact on women's personal autonomy. Their lack of financial autonomy has been identified as a factor fuelling the HIV epidemic in women in developing countries. ${ }^{33}$ Likewise, gender violence is more frequent and more brutal in countries where women are relegated to a lower social status. ${ }^{34} 35$

People who migrate are not always the poorest or the least educated, nor is their social status in their country of origin necessarily low. This applies to both men and women but may affect women differentially, since they are more prone to losing status, especially as observed in recent migrations to southern 
Europe, which have been characterised by high levels of irregular employment among women. ${ }^{66-38}$ Others gain status, particularly among women going from homemaking to the labour market. Distance between the respective social positions enjoyed in the countries of origin and destination has been described as a determinant of poor mental health. ${ }^{39}$

Furthermore, the migration journey itself may involve dangers to physical and mental health, particularly in cases where migration is illegal. Women are more often victims of violence, abuse and rape. ${ }^{63} \mathrm{~A}$ particular phenomenon associated with immigration is the trafficking in women whose primary intention is economic immigration. This mostly affects young women and is associated with high levels of physical, psychological and sexual violence. An estimated two million individuals, mainly women and girls, are trafficked annually (approximately $2.3 \%$ of all female migrants). ${ }^{4}$

\section{Health determinants in countries of destination}

On arriving in their country of destination, migrants are confronted by a new physical and socioeconomic environment, which involves a series of interrelated factors that affect their health. The absence of a comprehensive model that would integrate these has led us to present a descriptive overview, ranging from more structural factors, such as entry status or employment, to more individual ones, such as individual health behaviour or use of health services.

Upon arrival, entry status, characterised by whether the prospective immigrant is in a regular or irregular administrative situation, sets the stage for life in the host country. Entry status often determines access to the labour market, residency and employment rights, ability to acquire legal citizenship, access to social services such as health and education, and access to language training and social security programmes. Women who enter as wives may need to have residence permits that depend on their husbands' consent, which makes them especially vulnerable to the latter's authority..$^{40-42}$

Ethnic density, the proportion of people of one's own ethnic background living in a particular area, could be a health risk or protective factor, and its role is the subject of debate. Studies showing a protective effect argue that this is mediated through enhanced social cohesion and support, and protection against racism. ${ }^{43-46}$ The detrimental effect on health has been attributed to poor economic and social investment in these areas. While a number of authors have studied the effect of ethnic density on both physical and mental health for various minority groups, no specific studies testing a differential effect on men and women have yet been published. High ethnic density could offer more protection to men, while women could be at risk of social isolation from the society at large and reinforcement of traditional gender roles, something that would, in turn, render any effort to adapt to the host culture even more stressful.

At a more proximal level, access to employment is the gateway to basic resources. Immigrants are segregated in the labour market and channelled towards jobs that are unskilled, poorly paid and demanding long hours; in short, generally precarious employment with little recognition of their rights. ${ }^{37}{ }^{47}$ Immigrant women are more likely to be in the submerged economy or unemployed than are men. ${ }^{37}$ The types of jobs offered to men and women are different, as are the risks to health involved. Women are directed to domestic and caretaking services, while men obtain jobs in sectors such as mining, construction or agriculture. The precariousness of the labour market for female immigrants means they are more prone to suffer violence and sexual harassment, since they often depend on their employers to obtain or retain their work permits. However, some developed countries give higher preference to immigrants with professional and technical skills needed in the local labour markets and these immigrants are not channelled towards unskilled jobs.

Neighbourhoods characterised by high unemployment may increase the risk of poor health among immigrants. ${ }^{69}$ Active work has been reported to be associated with better self rated health among immigrants ${ }^{50}$ and denial of work to be strongly associated with psychological distress, though unemployment seems to affect men's health more strongly than women's. ${ }^{51}$

A consequence of precarious employment, particularly during the first years after arrival, is poverty, which is a major challenge to health, as has indeed been recognised in the special report on poverty in Europe, ${ }^{37}$ Canada and the United States.

The health benefits to be derived from social networks and social support are particularly salient for immigrant populations. $^{52-54}$ Most immigrants risk social isolation: this is particularly true of housewives who have followed their husbands and have little opportunity to recreate a functional social network in their host country, and of immigrant women who work in domestic service, who are often invisible and have little chance of establishing social relationships. ${ }^{55}$ Men may have more chances of social interaction through the workplace. Social networks can be established within and outside their own ethnic groups, but their possible differential effects on mental and physical health is unclear. ${ }^{57} 58$

As has been described for elderly populations in the United States ${ }^{59}$ and Europe ${ }^{60}$ different kinds of social support may also have differential effects on the health of migrant women and men. ${ }^{61}$ It has been proposed that social networks, largely made up of family rather than friends or civic engagement, may actually prove harmful to migrant women's health, owing to social isolation and role engulfing. Although the importance of family networks is accepted, situations of negative influence can nevertheless occur. ${ }^{62}$

Immigrants belonging to visible minorities-namely, people who can easily be ascribed to an ethnic origin other than that of the majority-are often the subject of discrimination, ${ }^{63}{ }^{64}$ and women may thus face triple discrimination as immigrants, minorities and women. ${ }^{27}{ }^{65}{ }^{66}$ Racial/ethnic discrimination ${ }^{67}$ and cultural distance display strong associations with mental disorders among immigrants. ${ }^{57}$ This effect can be modified by coping skills and resilience, which depend on age, gender and occupation. To our knowledge, however, no studies have been conducted on gender specific coping mechanisms for discrimination in immigrant populations.

Violence is a strong risk factor for physical and mental health, and immigrants are more likely to suffer from violence because of discrimination. ${ }^{68}$ Immigrant women are at high risk of victimisation at work, as they may be subjected to ongoing, repeated sexual abuse, especially if they are undocumented and work in the sex industry, though this can also happen to female domestic workers, caregivers or attendants. Immigrant women are also likely to suffer domestic violence from abusive partners, particularly if they come from countries where male violence towards wives is tolerated. Furthermore, intimate partner violence may increase with time elapsed since immigration. $^{66}$

Before immigration, health behaviours are shaped by the values and social norms of the country of origin, but upon arrival in the host country, these may change. Determinants of such behavioural changes include both individual factors, such as social class, gender, age, ethnicity, length of stay and country of birth, and societal features of the host country, such as the availability of health and social services and the existence of an established, like, ethnic community, which may avoid or delay a cultural break. Health behaviours of migrant populations also converge with those of destination countries but this process is 


\section{What this paper adds}

This paper calls attention to the lack of empirical evidence and the need for conceptual development to link gender, migration and health.

\section{Policy implications}

A better understanding of the effects of immigration on health status with the adoption of a gender perspective is needed to improve health policy for migrants. quite complex, inasmuch as some of these behavioural changes are detrimental to health while others are protective. ${ }^{69}$ Among the women of some cultures, low alcohol and tobacco intake and certain reproductive patterns - earlier childbearing and longer breastfeeding-can protect them from certain cancers, ${ }^{70}$ but these behaviours are not sufficiently protective in the destination country to counterbalance newly adopted cardiovascular risk behaviours. ${ }^{71}$ It is difficult to generalise without considering the background risks in the origin and destination populations. For instance, the direction of change in cardiovascular risk may be very different depending upon whether the immigrant comes from and arrives in a country with high or low cardiovascular risk. ${ }^{71} 72$

Comprehensive information on immigrants' health behaviours and how they maintain, adopt or change preventive behaviours is increasingly available. ${ }^{73-75}$ However, less information is available on gender differences in health behaviours and behavioural change in immigrant populations. ${ }^{76}$

While many studies have examined the use of health services among immigrant populations, most of these lack a gender perspective. Findings are difficult to summarise, owing to heterogeneity across immigrant groups and health systems. Newcomers tend to be unfamiliar with the health system in the host country, ${ }^{77}$ and tend to overuse emergency room services. $^{78} 79$ In general, immigrants tend to underuse mental health services, ${ }^{80-82}$ with fewer psychiatric hospitalisations and more emergency and compulsory psychiatric hospitalisations. ${ }^{83-85}$ According to one of the few studies with a gender perspective, while a very low prevalence of psychiatric admissions was reported among female immigrants coming from countries that were geographically and culturally further away from Western societies, community prevalence of mental disease showed the prevalence of mental disorders in women to be double that of men, thus providing evidence of underutilisation of in-hospital mental services by immigrant women. ${ }^{86}$ This underutilisation could be because of a gender bias in diagnostic classification or lower likelihood of hospitalisation once diagnosis is established.

Finally, since family health care revolves around the women in the immigrant family, the importance of eliminating barriers that impede women's access to social and health services, is particularly relevant. ${ }^{87}$ Many of the so called cultural barriers to health services are, in fact, the result of the rigidity of the health services. ${ }^{88}$

\section{MEASUREMENT, REGISTRATION AND INTERPRETATION OF DATA IN HEALTH INFORMATION SYSTEMS ON DISEASE BURDEN AND HEALTH DETERMINANTS IN MALE AND FEMALE MIGRANTS}

Measuring the burden of disease and understanding the determinants of health among male and female migrant populations requires access to relevant information through health information systems and/or ad hoc studies, in order to develop appropriate preventive and healthcare services with a gender perspective. ${ }^{89}$ While there is an obvious need for data for administrative, political and health policy purposes, there is also an inherent risk of possible misuse and abuse of such data.
The variables used to classify migrants in health information systems are the subject's place of birth, sometimes that of the parents, plus various other details, such as nationality. Unfortunately, this information is not available in most health information systems, and when it is available, is seldom furnished with a breakdown by sex. Some health information systems also record the racial/ethnic background, which may provide some additional information as to the health status of the community to which the migrant will, eventually, be ascribed.

Another important variable that would be essential to take into account is socioeconomic status, though once again, this variable is not usually available in most health information systems. ${ }^{28} 2989$ Given that migrants are often poorer, care must be taken in dealing with confounding by socioeconomic status when measuring health outcomes in migrants. As well as confounding, effect modification by socioeconomic status needs to be tested since differences in health outcomes according to race/ethnicity or place of origin do persist at different levels of socioeconomic status. As women are, on the whole, poorer than men, socioeconomic effects are likely to be more important in their case. ${ }^{28}$

Unbiased population rates are difficult to estimate because appropriate denominators are often missing. Rates of disease in migrant communities are likely to be overestimated since undocumented migrants, the most deprived and vulnerable, have a higher probability of appearing in the numerator but are often missing from population denominators. Furthermore, population health surveys have very low response rates among the foreign born, particularly those who do not speak the host country language at home. ${ }^{90}$ This selection bias could have differential consequences for men and women.

Finally, the same reasoning as that given by Bhopal ${ }^{89}$ for presenting health outcomes by ethnic group, even if differences are not statistically significant, applies to sex. As Kaufman and Cooper noted, ethnic stratification provides a better understanding of absolute estimates of disease frequency, since it does not assume that the distribution of measured and unmeasured confounding is uniform for each stratum of ethnicity and, by the same token, country of origin ${ }^{91}$ and sex. Moreover, it is essential to provide health outcomes systematically stratified by sex, since gender should not be treated as a confounder.

\section{CONCLUSION}

Unanswered questions and knowledge gaps remain about the precise way in which gender interacts with other social health determinants to shape the health of migrant populations. Further research is thus called for to advance towards a conceptual model of health and migration that integrates a gender perspective. This model could guide research to identify gender specific stressors, resources and vulnerabilities, which could then be targeted by public health services in destination countries to promote a better and healthier life for all migrants, men and women alike.

\section{ACKNOWLEDGMENTS}

This paper has been partially financed by the Red de Investigación en Salud y Género (Proyecto: "Abordaje integral de la investigación en 
Salud y Género" (FIS GO3/042 y PIO50373 ) and by FIS (ISCIII-RETIC RD06/006).

\section{Authors' affiliations}

Alicia Llácer, Julia del Amo, Lucía Mazarrasa, Instituto Salud Carlos III, Madrid, Spain

María Victoria Zunzunegui, Técnicas Avanzadas de Investigación en Servicios de Salud (TAISS), Madtid, Spain and Université de Montréal, Montréal, Canada

Francisco Bolümar, Universidad de Alcalá, Madrid, Spain

Alicia Llácer, Francisco Bolùmar, Ciber de Epidemiología y Salud Pública (CIBERESP), Spain

\section{REFERENCES}

1 Zlotnik H. The global dimensions of female migration, Migration Information Source. Washington, DC: Migration Policy Institute, 1 March 2003. http:// www.migrationinformation.org/Feature/print.cfm? ID = 109

2 United Nations. Department of Economic and Social Affairs. Trends in total migrant stock: the 2005 revision CD-Rom documentation. Population Division United Nations, February 2006. http://www.un.org/esa/population/ publications/migration/UN_Migrant_Stock_Documentation_2005.pdf.

3 Boyd M, Grieco E. Women and migration: incorporating gender into international migration theory. Migration Information Source, 1 March 2003. http://www.migrationinformation.org/Feature/print.cfm?ID = 106

4 BRIDGE. Género y Migración. Brighton: BRIDGE/Instituto de Estudios de Desarrollo 2005. http://www.bridge.ids.ac.uk/reports_gend_CEP.html.

5 Oishi N. Gender and migration: an integrative approach. University of California, San Diego: CCIS The Center for Comparative Immigration Studies Working Paper 49 March, 2002:1-18.

6 United Nations. Department of Economic and Social Affairs. Division for the Advancement of Women. 2004 World survey on the role of women in development: women and international migration. United Nations 2005:1-97.

7 Sørensen N. Migrant remittances, development and gender. DIIS Brief, Copenhagen: Danish Institute for International Studies (DIIS) 2005. http:// www.diis.dk/graphics/Publications/Briefs2005/nns_migrant_remittances.pdf.

8 Fondo de Población de las Naciones Unidas (UNFPA). El estado de la población mundial 2006. Hacia la esperanza: Las mujeres y la migración internacional. UNFPA 2006:5-107.

9 Rolfhs I, Mazarrasa L, Género y Salud, et al, eds. Salud Pública y Enfermería Comunitaria. 2nd ed. Madrid: McGraw-Hill Interamericana, 2003:533-53.

10 Rohlfs I, Borrell C, Fonseca M do C. [Gender inequalities and public health: awarenesses and ignorances.] Gac Sanit 2000;14(suppl 3):60-71.

11 Amorós C (directora). 10 palabras clave sobre mujer. Estella: Verbo Divino 1998:7-84

12 United Nations. Department of Economic and Social Affairs. Recommendations on statistics of international migration. New York: United Nations: Statistical Papers Series M, Rev 1998;1:9-25.

13 Hyman I, Guruge S. A review of theory and health promotion strategies for new immigrant women. Can J Public Health 2002;93:183-7.

14 Im EO, Yang K. Theories on immigrant women's health. Health Care Women Int 2006;27:666-681.

15 Razum O, Zeeb H, Rohrmann S. The 'healthy migrant effect' - not merely a fallacy of inaccurate denominator figures. Int J Epidemiol 2000;29:191-2.

16 Newbold KB. Health status and health care of immigrants in Canada: a longitudinal analysis. J Health Serv Res Policy 2005; 10:77-83.

17 Newbold KB. Self-rated health within the Canadian immigrant population: risk and the healthy immigrant effect. Soc Sci Med 2005;60:1359-70.

18 Kennedy S, McDonald JT, Biddle N. The healthy immigrant effect and immigrant selection: evidence from four countries. Social and Economic Dimensions of an Aging Population Research Papers 164. McMaster University, 2006.

19 Franzini L, Ribble JC, Keddie AM. Understanding the Hispanic paradox. Ethn Dis $2001 ; 11: 496-518$

20 Markides KS, Eschbach K. Aging, migration, and mortality: current status of research on the Hispanic paradox. J Gerontol B Psychol Sci Soc Sci 2005;60(Spec No 2):68-75

21 Palloni A, Arias E. Paradox lost: explaining the Hispanic adult mortality advantage. Demography 2004;41:385-415.

22 Khlat M, Darmon N. Is there a Mediterranean migrants mortality paradox in Europe? Int J Epidemiol 2003;32:1115-8.

23 Razum O, Zeeb H, Akgun HS, et al. Low overall mortality of Turkish residents in Germany persists and extends into a second generation: merely a healthy migrant effect? Trop Med Int Health 1998;3:297-303.

24 Razum O. Commentary: of salmon and time travellers-musing on the mystery of migrant mortality. Int J Epidemiol 2006;35:919-21.

25 Harding S, Balarajan R. Mortality of third generation Irish people living in England and Wales: longitudinal study. BMJ 2001;322:466-7.

26 Scanlon K, Harding S, Hunt K, et al. Potential barriers to prevention of cancers and to early cancer detection among Irish people living in Britain: a qualitative study. Ethn Health 2006;11:325-41.

27 Beiser M. The health of immigrants and refugees in Canada. Can J Public Health 2005;96(Suppl 2):S30-S44.

28 Cooper H. Investigating socio-economic explanations for gender and ethnic inequalities in health. Soc Sci Med 2002;54:693-706.
29 Smith GD. Learning to live with complexity: ethnicity, socioeconomic position, and health in Britain and the United States. Am J Public Health 2000;90:1694-8.

30 Wallerstein $\mathrm{N}$. What is the evidence on effectiveness of empowerment to improve health? Copenhagen: WHO Regional Office for Europe (Health Evidence Network report, 2006. http://www.euro.who.int/Document/E88086.pdf, [accessed 13 April 2007]).

31 Hammarstrom A, Ripper M. What could a feminist perspective on power bring into public health? Scand J Public Health 1999;27:286-9.

32 Ezzati M, Lopez AD, Rodgers A, et al. Selected major risk factors and global and regional burden of disease. Lancet 2002;360:1347-60.

33 Periago MR, Fescina R, Ramon-Pardo P. Steps for preventing infectious diseases in women. Emerg Infect Dis 2004;10:1968-73.

34 Organización Mundial de la Salud. Estudio multipaís de la OMS sobre salud de la mujer y violencia doméstica contra la mujer, Organización Mundial de la Salud, 2005.

35 Organización Panamericana de la Salud. Informe mundial sobre la violencia y la salud: resumen. Washington, DC: Organización Panamericana de la Salud, Oficina Regional para las Américas de la Organización Mundial de la Salud, 2002.

36 Aubarell G. Una propuesta de recorrido bibliográfico de las migraciones femeninas en España. OFRIM suplementos. Papers 2000;60:392-413.

37 Caritas. Migration, a journey into poverty. A Caritas Europe Study on poverty and social exclusion of immigrants in Europe, Third report of Poverty in Europe.Brussels, June, 2006:7-106.

38 loé. Mujer, Inmigración y Trabajo. Madrid: Editorial IMSERSO, Ministerio de Trabajo y Asuntos Sociales, 2001

39 Bhugra D. Migration and mental health. Acta Psychiatr Scand 2004;109:243-58.

40 Raj A, Silverman JG, McCleary-Sills J, et al. Immigration policies increase south Asian immigrant women's vulnerability to intimate partner violence. J Am Med Womens Assoc 2005:60:26-32.

41 Kasturirangan A, Krishnan S, Riger S. The impact of culture and minority status on women's experience of domestic violence. Trauma Violence Abuse 2004:5:318-32

42 Sokoloff NJ, Dupont I. Domestic violence at the intersections of race, class, and gender: challenges and contributions to understanding violence against marginalized women in diverse communities. Violence Against Women 2005;11:38-64.

43 Halpern D, Nazroo J. The ethnic density effect: results from a national community survey of England and Wales. Int J Soc Psychiatry 2000;46:34-46.

44 Karlsen S, Nazroo JY, Stephenson R. Ethnicity, environment and health: putting ethnic inequalities in health in their place. Soc Sci Med 2002;55:1647-61

45 Karlsen S, Nazroo JY. Relation between racial discrimination, social class, and health among ethnic minority groups. Am J Public Health 2002;92:624-31.

46 Nazroo JY. The structuring of ethnic inequalities in health: economic position, racial discrimination, and racism. Am J Public Health 2003;93:277-84.

47 Akhavan S, Bildt CO, Franzen EC, et al. Health in relation to unemployment and sick leave among immigrants in Sweden from a gender perspective. J Immigr Health 2004;6:103-18.

48 Oxman-Martinez J, Abdool SN, Loiselle-Leonard M. Immigration, women and health in Canada. Can J Public Health 2000;91:394-5.

49 Zunzunegui MV, Forster M, Gauvin L, et al. Community unemployment and immigrants' health in Montreal. Soc Sci Med 2006;63:485-500.

50 Newbold KB, Danforth J. Health status and Canada's immigrant population. Soc Sci Med 2003;57:1981-95.

51 Thapa SB, Hauff E. Gender differences in factors associated with psychological distress among immigrants from low- and middle-income countries--findings from the Oslo Health Study. Soc Psychiatry Psychiatr Epidemiol 2005;40:78-84.

52 Wong ST, Yoo GJ, Stewart AL. An empirical evaluation of social support and psychological well-being in older Chinese and Korean immigrants. Ethn Health 2007; 12:43-67

53 Litwin H. Social networks and self-rated health: a cross-cultural examination among older Israelis. J Aging Health 2006;18:335-58

54 Hyman I, Dussault G. Negative consequences of acculturation on health behaviour, social support and stress among pregnant Southeast Asian immigrant women in Montreal: an exploratory study. Can J Public Health 2000;91:357-60.

55 Conseil du Statut de la femme. Les femmes immigrées du Québec. Québec, Canada, 2005. http://www.csf.gouv.qc.ca/telechargement_publication/ index.php?id $=255$

56 Im EO, Meleis Al. Women's work and symptoms during midlife: Korean immigrant women. Women Health 2001;33:83-103.

57 Bhugra D, Becker MA. Migration, cultural bereavement and cultural identity. World Psychiatry 2005;4:18-24

58 Bhugra D, Arya P. Ethnic density, cultural congruity and mental illness in migrants. Int Rev Psychiatry 2005;17:133-7.

59 Fiori KL, Antonucci TC, Cortina KS. Social network typologies and mental health among older adults. J Gerontol B Psychol Sci Soc Sci 2006;61:25-32

60 Litwin H. Social network type and morale in old age. Gerontologist $2001 ; 41: 516-24$

61 Levy-Storms L, Lubben JE. Network composition and health behaviors among older Samoan women. J Aging Health 2006;18:814-36.

62 Grewal S, Bottorff JL, Hilton BA. The influence of family on immigrant South Asian women's health. J Fam Nurs 2005; 11:242-63.

63 Finch BK, Kolody B, Vega WA. Perceived discrimination and depression among Mexican-origin adults in California. J Health Soc Behav 2000;41:295-313.

64 Noh S, Avison WR. Asian immigrants and the stress process: a study of Koreans in Canada. J Health Soc Behav 1996:37:192-206. 
65 Vissandjee B, Desmeules M, Cao Z, et al. Integrating ethnicity and migration as determinants of Canadian women's health. BMC Womens Health 2004;4(Suppl 1):S32.

66 Hyman I, Forte T, Du MJ, et al. The association between length of stay in Canada and intimate partner violence among immigrant women. Am J Public Health 2006:96:654-9.

67 Bhui K, Stansfeld S, McKenzie K, et al. Racial/ethnic discrimination and common mental disorders among workers: findings from the EMPIRIC Study of Ethnic Minority Groups in the United Kingdom. Am J Public Health 2005;95:496-501

68 Noh S, Kaspar V. Perceived discrimination and depression: moderating effects of coping, acculturation, and ethnic support. Am J Public Health 2003;93:232-8.

69 Singh GK, Hiatt RA. Trends and disparities in socioeconomic and behavioural characteristics, life expectancy, and cause-specific mortality of native-born and foreign-born populations in the United States, 1979-2003. Int J Epidemiol 2006;35:903-19

70 Kliewer EV, Smith KR. Breast cancer mortality among immigrants in Australia and Canada. J Nat Cancer Inst 1995:87:1154-61.

71 Rubia M, Marcos I, Muennig PA. Increased risk of heart disease and stroke among foreign-born females residing in the United States. Am J Prev Med 2002;22:30-5.

72 Gadd $M$, Johansson SE, Sundquist J, et al. Are there differences in all-cause and coronary heart disease mortality between immigrants in Sweden and in their country of birth? A follow-up study of total populations. BMC Public Health 2006;6:102.

73 Im EO, Choe MA. Physical activity of Korean immigrant women in the US: needs and attitudes. Int J Nurs Stud 2001;38:567-77.

74 Lindstrom M, Sundquist K. The impact of country of birth and time in Sweden on overweight and obesity: a population-based study. Scand J Public Health 2005;33:276-84.

75 McDonald JT, Kennedy S. Is migration to Canada associated with unhealthy weight gain? Overweight and obesity among Canada's immigrants. Soc Sci Med 2005;61:2469-81.

76 Otero-Sabogal R, Sabogal F, Perez-Stable EJ, et al. Dietary practices, alcohol consumption, and smoking behavior: ethnic, sex, and acculturation differences. J Natl Cancer Inst Monogr 1995:73-82.

77 Zanchetta MS, Poureslami IM. Health literacy within the reality of immigrants' culture and language. Can J Public Health 2006;97(Suppl 2):S26-S30.
78 Cots F, Castells X, Garcia O, et al. Impact of immigration on the cost of emergency visits in Barcelona (Spain). BMC Health Serv Res 2007:7:9.

79 Norredam M, Krasnik A, Moller ST, et al. Emergency room utilization in Copenhagen: a comparison of immigrant groups and Danish-born residents. Scand J Public Health 2004;32:53-9.

80 Anagnostopoulos DC, Vlassopoulou M, Rotsika V, et al. Psychopathology and mental health service utilization by immigrants' children and their families. Transcult Psychiatry 2004;41:465-86.

81 Fenta H, Hyman I, Noh S. Mental health service utilization by Ethiopian immigrants and refugees in Toronto. J Nerv Ment Dis 2006;194:925-34.

82 Vega WA, Kolody B, Aguilar-Gaxiola S, et al. Gaps in service utilization by Mexican Americans with mental health problems. Am J Psychiatry $1999 ; 156: 928-34$

83 Lay B, Lauber C, Rossler W. Are immigrants at a disadvantage in psychiatric inpatient care? Acta Psychiatr Scand 2005;111:358-66.

84 Lay B, Lauber C, Nordt C, et al. Patterns of inpatient care for immigrants in Switzerland: A case control study. Soc Psychiatry Psychiatr Epidemiol 2006;41:199-207.

85 Mulder CL, Koopmans GT, Selten JP. Emergency psychiatry, compulsory admissions and clinical presentation among immigrants to the Netherlands. Br J Psychiatry 2006;188:386-91.

86 Lay B, Nordt C, Rossler W. Mental hospital admission rates of immigrants in Switzerland. Soc Psychiatry Psychiatr Epidemiol 2007;42:229-236.

87 Stewart MJ, Neufeld A, Harrison MJ, et al. Immigrant women family caregivers in Canada: implications for policies and programmes in health and social sectors. Health Soc Care Community 2006;14:329-40.

88 Sword W, Watt S, Krueger P. Postpartum health, service needs, and access to care experiences of immigrant and Canadian-born women. J Obstet Gynecol Neonatal Nurs 2006;35:717-27.

89 Bhopal R. Ethnicity and race as epidemiological variables: centrality of purpose and context. In: Health and Ethnicity. London: Taylor \& Francis, 2001.

90 Jetté M, Des Groseilliers L. L'enquête: description et méthodologie dans Étude longitudinale du développement des enfants du Québec (ÉLDEQ 1998-2002). Québec: Institut de la statistique du Québec, 2000;1(1).

91 Kaufman JS, Cooper RS. Commentary: considerations for use of racial/ethnic classification in etiologic research. Am J Epidemiol 2001;154:291-8. 